blunt instruight, ind the rephalepsalis, and that it was by inadvertence shown ta me (not by himgelf) at the same time with the kephalepsalis.

Mr Simpson farther states, that he has in his possession a correct specimen of my father's instrument, competent (as it should We) to remove finely ent sections from a piece of writing paper without the least trace of a ragged edge.

I am obliged to Mr. Simpson for his communication, as it enables me to remove an impression which an observation in my last letter was calculated to convey to his prejudice, implying that he had made an unfair comparison, and of which I entirely acquit him." I am, Sir, your obedient servant,

John Hall Davis, M.D.,

Physician-Accoucheur to the Royal Maternity Charity.

17, Russell-place, Fitzroy-square, May 3, 1842.

P.S. - The osteotomist may be seen at $\mathrm{Mr}$. Botschan's, 35, Worship-street, Finsburysquare ; Mr. Coxeter's, Grafton-street East, University College, London.

\section{INACCURACY OF DISPENSING CHEMISTS.}

\section{To the Editor of THE LANCET.}

Srr,-On Saturday last a physician in my neighbourhood saw a little patient of mine, and prescribed the following powders :-

R Pulv. Jacob., grs. iij ;

Potass nit., grs. ix ;

P. trug, comp., grs. xv. Ft. Pulv. omni nocte sumendus.

On returning home, the mother called in at a respectable chemist's shop to get the prescription dispensed, when she received three white powders weighing only ten grains each : on my calling and looking at the prescription and powders, I remarked they were too small, and directed the preseription to be sent to another chemist, when to my surprise the same quantity of white powder -was put up and sent: Does not this corroborate what $I$ wrote on this subject in The Lancep on the I5th of May, 1841, signed "Medicus?" I am, Sir, your obedient servant,

Mày $5,1842$.

M. Rowe.

\section{MEDICAL OFFICERS OF HOSPITALS.}

\section{To the Editor of The LANCET.}

S1R,-At the last anniversary meeting of the North of England Medical Association, a report was read by Dr. Glever, from a committee appointed by the council of that body to consider the subject of medical ap. pointments to hospitals and other public charities: in which report was contained a recommendation, that where pure physicians or pure surgeons could be found, the preference should be given to them over general practi. tioners. Does the association think that they can have the support of the geveral pratitioner, while they authorise reports that are thus calculated to injure, by libelling, nearly the whole body of medical practitioners of this country?

But I am indeed surprised, when I recol. lect that the persons who were the advocates of this report were either general praetitio. ners, or had lately been so. This report was brought forward, as I have before said, by a Dr. Glover, who only a few months ago was a general practitioner himself, but who has lately obtained a Scotch degree, and bas set up as a pure physician. It was also sup. ported by Dr. Embleton, who has only within the last few months taken from of his brass plate the word " surgeon, \&e." Thus it would appear that the two "pures" are now qualified for the office of physicians to public charities, which they were not a fer months ago. Upon their own arguments, they were not competent for such affices a few months ago. But what surprised me the most was, that the report was supported by so intelligent and good a practitioner as Mr. T. M. Greenhow, who is a general practitioner, and one of the surgeons to the Nerr. castle Infirmary, and to the Eye Intirmary, and the Gaol. This is what the Yankees would call an " everlasting awkward fis;" for either Mr. G. is, according to the logic of the "pures," unfit to hold the offices which he does hold, or else they have made a few exceptions.

But I would like to be informed on what grounds a general practitioner is to be considered inferior either in talents or station to a pure physician with a Scotch or foreign degree. I should also like to know why a surgeon who is a general practitioner is less qualified to perform surgical operations, on account of his acting in a medical capacity. Where, moreover, are the "f pure" surgeons to be found in the provinces; I do-not believe that there will be found a pure surgeon out of London or Edinburgh in England. -But if they were as plentiful as pure physicians, I do not think that they are better fitted to fill the situations as hospital-sul* geons; but that the general practitioner is better qualified than the pure, whise practice must necessarily be exceedingly limited, and consequently his experience mach less than that of the general practitioner. I main, Sir, yours truly,

\section{A General Practimoneri.}

\section{Literary Society's. Rooms,}

Newcastle-on-Tyne, May 2, 1848. 